\title{
Role of Insulin Resistance in Adipose Tissue and Liver in the Pathogenesis of Endogenous Hypertriglyceridaemia in Man
}

\author{
A. H. Kissebah, S. Alfarsi, P. W. Adams and V. Wynn \\ The Alexander Simpson Laboratory for Metabolic Research, St. Mary's Medical School, London, England
}

Summary. Studies were performed to evaluate the relative importance of enhanced adipose tissue lipolysis and increased insulin levels in modulating hepatic VLDL production in patients with endogenous hypertriglyceridaemia. Eight control subjects and nine patients with hypertriglyceridaemia were investigated. The latter group comprised four patients with idiopathic hypertriglyceridaemia, three maturity onset diabetics, and two siblings with diabetic lipodystrophy. Each individual's plasma VLDL was selectively labelled with $\mathrm{I}^{131}$ in the apoprotein moiety and then reinjected to assess the turnover of these molecules. This was correlated with the insulin response to an oral glucose load and with the plasma FFA flux measured by a continuous infusion of ${ }^{14} \mathrm{C}$ palmitate. In the patients with idiopathic hypertriglyceridaemia and in the adult onset diabetics, plasma VLDL-apoprotein turnover was increased suggesting enhanced hepatic production of these molecules. Although the insulin levels in these patients were higher than normal, no significant correlation was demonstrable between the plasma insulin and the turnover of VLDL-B-apoprotein. Furthermore, in the two patients with lipo-dystrophy the turnover of plasma VLDL was within the normal range, whereas the plasma insulin responses were the highest among all the patients. These results suggest that hyperinsulinaemia alone is not sufficient to account for the increased VLDL production seen in some of our patients. The plasma FFA flux was raised in the patients with idiopathic hypertriglyceridaemia and in the maturity onset diabetics, and was within the normal range in the two patients with lipodystrophy. Indeed, in all the subjects studied a significant correlation was observed between the turnover of plasma VLDL-B-apoprotein and the plasma FFA flux. The results thus indicate that the rate of FFA release to plasma constitutes the predominant factor in determining hepatic output of
VLDL and that in the majority of patients with endogenous hypertriglyceridaemia the increased FFA flux resulting from insulin resistance in adipose tissue could effectively increase VLDL production. This process appears to be independent of the prevailing insulin levels, and could occur in the presence of insulin resistance in the liver. The latter, however, could be responsible for the impaired glucose tolerance observed in some patients.

Key words: Insulin resistance, endogenous hypertriglyceridaemia, maturity onset diabetes, diabetic lipodystrophy, very low density lipoproteins (VLDL) VLDL-B-apoproteins, free fatty acids (FFA), insulin.

Insulin is an important lipogenic hormone and, by way of its effects on lipid metabolism may play an important role in the pathogenesis of hypertriglyceridaemia. Farquhar et al. [1] were the earliest to demonstrate a close correlation between the postprandial rise in plasma insulin and the elevation of plasma triglyceride concentration, suggesting that the hypertriglyceridaemia in these subjects was secondary to the hyperinsulinaemia.

Further studies by Reaven et al. [2] and Olefsky et al. [3] have indicated that patients with elevated triglyceride levels have diminished peripheral tissue responsiveness to insulin and that the compensatory hyperinsulinaemia correlates with the increased triglyceride production seen in these patients. It was therefore postulated that hyperinsulinaemia is the main abnormality stimulating the hepatic synthesis of fatty acids from carbohydrate sources, which in turn enhances hepatic triglyceride production, resulting in hypertriglyceridaemia. This hypothesis has been criti- 
Table 1. Age, body weights, plasma lipid concentration and VLDL composition in the groups studied

\begin{tabular}{|c|c|c|c|c|c|c|c|c|}
\hline \multirow{2}{*}{$\begin{array}{l}\text { Subject } \\
\text { No. }\end{array}$} & \multirow{2}{*}{$\begin{array}{l}\text { Age } \\
\text { yrs }\end{array}$} & \multicolumn{2}{|c|}{ Body weight } & \multicolumn{2}{|c|}{ Plasma conc. $(\mathrm{mg} / 100 \mathrm{ml})$} & \multicolumn{3}{|c|}{ Plasma VLDL conc. $(\mathrm{mg} / 100 \mathrm{ml})$} \\
\hline & & $\mathrm{Kg}$ & $\%$ ideal & Trig. & Chol. & Trig. & $\begin{array}{l}\text { Total } \\
\text { protein }\end{array}$ & B-apoprotein \\
\hline \multicolumn{9}{|c|}{ Normotriglyceridaemic subjects $(n=8)$} \\
\hline 1 & 46 & 55 & 96 & 90 & 162 & 52 & 10 & 5.5 \\
\hline 2 & 37 & 82 & 115 & 128 & 238 & 87 & 14 & 8.8 \\
\hline 3 & 45 & 53 & 90 & 109 & 196 & 72 & 13 & 6.8 \\
\hline 4 & 66 & 66 & 110 & 100 & 164 & 56 & 9 & 4.8 \\
\hline 5 & 35 & 68 & 95 & 69 & 142 & 46 & 7 & 3.5 \\
\hline 6 & 43 & 91 & 112 & 158 & 220 & 118 & 2.8 & 12.7 \\
\hline 7 & 33 & 72 & 94 & 150 & 216 & 104 & 25 & 11.6 \\
\hline 8 & 35 & 64 & 116 & 68 & 228 & 40 & 15 & 9.1 \\
\hline $\begin{array}{l}\text { Mean } \pm \\
\text { Range }\end{array}$ & $\begin{array}{r}43 \pm 4 \\
(35-66)\end{array}$ & $\begin{array}{l}69 \pm 4 \\
(53-91)\end{array}$ & $\begin{array}{l}104 \pm 4 \\
(94-116)\end{array}$ & $\begin{array}{l}109 \pm 12 \\
(68-158)\end{array}$ & $\begin{array}{l}196 \pm 13 \\
(142-238)\end{array}$ & $\begin{array}{l}72 \pm 10 \\
(40-118)\end{array}$ & $\begin{array}{l}15 \pm 3 \\
(7-28)\end{array}$ & $\begin{array}{l}8.0 \pm 1.1 \\
(3.5-12.7)\end{array}$ \\
\hline \multicolumn{9}{|c|}{ Endogenous hypertriglyceridaemia $(n=.7)$} \\
\hline 9 & 32 & 107 & 115 & 328 & 384 & 264 & 54 & 27 \\
\hline 10 & 40 & 89 & 109 & 254 & 256 & 199 & 33 & 15 \\
\hline 11 & 45 & 75 & 111 & 354 & 318 & 310 & 52 & 21 \\
\hline 12 & 54 & 105 & 122 & 360 & 280 & 286 & 38 & 18 \\
\hline 13 & 46 & 86 & 126 & 420 & 168 & 386 & 76 & 46 \\
\hline 14 & 38 & 67 & 105 & 740 & 169 & 660 & 110 & 59 \\
\hline 15 & 52 & 74 & 116 & 630 & 280 & 540 & 98 & 54 \\
\hline Mean \pm & $144 \pm 3$ & $86 \pm 6$ & $115 \pm 3$ & $441 \pm 67$ & $265 \pm 29$ & $377 \pm 62$ & $66 \pm 11$ & $34 \pm 6.9$ \\
\hline Range & $(32-54)$ & $(67-107)$ & $(105-126)$ & $(254-740)$ & $(168-384)$ & $(199-660)$ & $(33-110)$ & $(15-59)$ \\
\hline \multicolumn{9}{|c|}{ Lipodystrophic diabetes $(n=2)$} \\
\hline 16 & 36 & 52 & 86 & 380 & 220 & 310 & 62 & 37 \\
\hline 17 & 39 & 46 & 78 & 415 & 238 & 365 & 68 & 43 \\
\hline
\end{tabular}

$\mathrm{N}=$ number of subjects investigated

Trig = triglycerides, Chol = cholesterol

cised on the basis that if insulin resistance is a primary defect in these patients, it is more likely to affect all tissues sensitive to insulin, including the liver [4], and consequently hyperinsulinaemia could not stimulate hepatic lipogenesis. Indeed, studies in animals with genetically determined insulin resistance have shown this defect to be global, involving the liver in addition to adipose tissue and skeletal muscle $[5,6]$.

An alternative hypothesis $[7,8]$ has been proposed by our group suggesting that the increased VLDL production in endogenous hypertriglyceridaemia is a manifestation of enhanced lipolysis secondary to insulin resistance in adipose tissue. Since plasma free fatty acids (FFA) constitute the major precursor for hepatic triglyceride synthesis $[9,10]$, the increased supply of FFA could stimulate the production of plasma VLDL. This process appears to be independent of the actions of insulin on the liver and consequently the insulin resistance in patients with endogenous hypertriglyceridaemia could be global. We have, therefore, suggested that the effects of hyperinsulinaemia on the liver are not of primary importance in the development of hypertriglyceridaemia and that the insulin resistance in adipose tissue constitutes the major determinant factor in this syndrome.
To assess our hypothesis, we have measured the plasma FFA flux and turnover rates of plasma VLDL in nine hypertriglyceridaemic patients with hyperinsulinaemia. Four had idiopathic hypertriglyceridaemia and three maturity onset diabetes, in whom the hyperinsulinaemia was associated with increased plasma FFA levels. The remaining two patients had lipodystrophic diabetes and their hyperinsulinaemia was associated with normal FFA levels.

\section{Material and Methods}

\section{Subjects}

Eight normal subjects and nine male patients with endogenous hypertriglyceridaemia were investigated. The latter group included four patients with idiopathic hypertriglyceridaemia, three patients with maturity onset diabetes und two siblings with diabetic lipodystrophy. The normolipaemic group comprised healthy volunteers with serum trilgyceride concentrations less than $160 \mathrm{mg} / 100 \mathrm{ml}$. None of these subjects had abnormal glucose tolerance (fasting plasma glu- 
cose less than $100 \mathrm{mg} / 100 \mathrm{ml}, 60 \mathrm{~min}$ and $120 \mathrm{~min}$ values less than 180 and $120 \mathrm{mg} / 100 \mathrm{ml}$ respectively). Their ages, body weights and percentage of their ideal body weights are shown in Table 1 .

The ages and body weights of the hyperlipaemic patients are also shown in Table 1 . None of the patients were obese (body weight less than $130 \%$ of their ideal, calculated from Documenta Geigy). Three of the idiopathic hypertriglyceridaemic patients $[9,10$, 12] presented with eruptive xanthomatosis and the fourth [11] was detected on biochemical screening. The diabetic patients $[13,14,15]$ were asymptomatic and were found to have abnormal glucose tolerance during routine investigation.

The lipodystrophic subjects were two male siblings who presented with this syndrome five years ago. Loss of subcutaneous fat was evident in photographs since adolescence. Hepatomegaly was not marked on clinical examination and no abnormalities of renal or liver function were detected on biochemical screening.

Both the normal subjects and the patients with hyperlipaemia were stabilised on an isocaloric diet providing 35 calories per $\mathrm{kg}$ body weight, of which $38 \%$ was in the form of carbohydrate, $45 \%$ fat and $17 \%$ protein. This diet was maintained throughout the whole study during which time the body weight of the subjects remained constant. Clinical and laboratory investigations showed no evidence of thyroid disease or excessive alcoholism, and none of the subjects were taking any drugs known to affect lipid metabolism. Informed consent was obtained from all subjects before they entered into the investigation.

\section{Methods}

\section{A. Plasma VLDL-Apoprotein Turnover}

1. Preparation of ${ }^{131} \mathrm{I}$ VLDL. Very low density lipoproteins $(\mathrm{d}<1.006)$ were prepared from 50 to $100 \mathrm{ml}$ of fasting plasma obtained from each patient using preparative ultracentrifugation [11]. The lipoprotein fraction was then concentrated and washed by two successive centrifugations at the same density. After adjusting the $\mathrm{pH}$ of the lipoprotein mixture with glycine buffer $(1 \mathrm{M}, \mathrm{pH} 10),{ }^{131} \mathrm{I}$ was introduced into the VLDL molecule using the iodine monochloride jet technique of McFarlane [12]. The unbound radioiodine was then removed by repeated dialysis against $6-10$ changes of $0.9 \%$ saline, containing $0.01 \%$ EDTA, for a total period of 6-8 h. Paper chromatography [13] of the dialysed material in methanol:water $(85: 15, \mathrm{~V} / \mathrm{V})$, has shown that less than $4 \%$ of the total radioactivity was unbound radiodine.
Table 2. Distribution of radioactivity among the major components of plasma.VLDL before and after in-vitro incubation with HDL rich plasma

\begin{tabular}{|c|c|c|c|c|}
\hline \multirow[t]{2}{*}{ Subjects } & \multirow{2}{*}{$\begin{array}{l}\text { Experimental } \\
\text { conditions }\end{array}$} & \multicolumn{3}{|c|}{$\%$ of the total radioactivity } \\
\hline & & $\begin{array}{l}\text { B-apo- } \\
\text { protein }\end{array}$ & $\begin{array}{l}\text { C-apo- } \\
\text { protein }\end{array}$ & $\begin{array}{l}\text { Total } \\
\text { lipids }\end{array}$ \\
\hline \multicolumn{5}{|c|}{ Normotriglyceridaemic subjects } \\
\hline $\mathrm{n}=8$ & $\begin{array}{l}\text { unincubated } \\
\text { postincubated }\end{array}$ & $\begin{array}{l}59(52-68) \\
88(83-98)\end{array}$ & $\begin{array}{l}30(24-33) \\
8(2-11)\end{array}$ & $\begin{array}{l}11(8-15) \\
4(2-7)\end{array}$ \\
\hline \multicolumn{5}{|c|}{ Hypertriglyceridaemic patients } \\
\hline $\mathrm{n}=9$ & $\begin{array}{l}\text { unincubated } \\
\text { postincubated }\end{array}$ & $\begin{array}{l}46(38-62) \\
89(82-94)\end{array}$ & $\begin{array}{l}33(26-38) \\
6(2-9)\end{array}$ & $\begin{array}{l}21(16-26) \\
5(3-8)\end{array}$ \\
\hline
\end{tabular}

Values in the table show the means while the values between parenthesis represent the range in each group. Plasma VLDL was isolated, concentrated and iodinated with $\mathrm{I}^{131}$ as described under Methods; Aliquots of the iodinated material were removed for determination of radioactivity distribution. The labelled lipoproteins were then incubated with the patients' own HDL rich plasma for 4 hours at $4^{\circ} \mathrm{C}$ and separated by centrifugation. Thereafter the distribution of label in the major components was determined. The B-apoprotein was separated from the C-apoprotein by tetramethylurea precipitation while the lipids were extracted in chloroform methanol $(2: 1, \mathrm{~V}: \mathrm{V})$

Table 2 shows the percentage distribution of radioactivity among the major constituents of plasma VLDL labelled by this technique. Lipids were extracted in chloroform:methanol $(2: 1, \mathrm{~V} / \mathrm{V})$ and the major components were separated on thin layer chromatography [14]. 8-26\% of the total isotope in VLDL was recovered in the lipid extract, mainly as cholesterol esters (36\%), phospholipids (38\%), triglycerides $(18 \%)$ and unesterified cholesterol $(8 \%)$. Following precipitation of the B-apoprotein with tetramethylurea [15], 24-38\% of the total radioactivity was found in the supernatant containing the C-apoproteins. The B-apoproteins were therefore found to contain $38-68 \%$ of the total radioactivity.

In order to study the metabolic behaviour of the B-apoprotein without interference from other labelled components in VLDL the lipoproteins were preincubated for four hours with the patient's own HDL rich plasma remaining after separation of VLDL and LDL. Thereafter the VLDL fraction was re-isolated by ultracentrifugation. Since the C-apoproteins and some of the lipids in VLDL undergo rapid exchange with similar unlabelled components in HDL [16] this incubation step resulted in a reduction in the percentage of total label present in these components while the radioactivity in the B-apoprotein was retained. Table 2 shows that $82-98 \%$ of the total radioactivity in preincubated VLDL resided in the B-apoprotein moiety. 
2. Injection of Radioactive Lipoproteins and Collection of Samples. All reagents used for the preparation of labelled lipoproteins were made in pyrogen free distilled water and kept in sterile containers. Before injection into the patients the lipoproteins were passed through a Millipore filter $(0.45 \mu)$ and diluted in sterile saline. All subjects were given Lugol's iodine 5 drops per day beforehand to block the uptake of free radioactive iodine by the thyroid and to facilitate its immediate excretion in urine.

Patients were admitted to the metabolic ward and after an overnight fast an indwelling catheter was inserted into the antecubital vein for injection. Another catheter was introduced into the superior vena cava via a contralateral arm vein for sampling. Each patient received $6-8 \mathrm{mg}$ of his own plasma VLDL labelled in the B-apoprotein moiety with ${ }^{131} \mathrm{I}(25-40 \mu \mathrm{Ci})$. The total dose of radioactive material injected into each subject was checked by accurate weighing of syringe contents, and standards were prepared from aliquots to be used as a reference during the counting of blood samples.

The radioactive material was administered as a pulse injection and a blood sample was obtained ten minutes after the injection and at one hour intervals for the first twelve hours. Thereafter samples were obtained every two hours for a further period of twelve hours. During this period patients were given low fat meals ( $<5 \mathrm{~g} /$ day) which maintained steady state levels of plasma VLDL concentration.

Samples of blood were immediately spun at $4 C^{\circ}$ to separate the plasma. The VLDL fraction in each sample was prepared by ultracentrifugation and aliquots were then removed for determination of radioactivity. The B-apoprotein in plasma VLDL was separated from the $\mathrm{C}$-apoprotein using the tetramethylurea precipitation technique of Kane [15] and the protein content was estimated by the method of Lowry et al. [17].

3. Interpretation of Data and Calculations. The ${ }^{131} \mathrm{I}$ radioactivity present in VLDL per litre of plasma was expressed as a percentage of the corresponding dose of radioactivity injected into each patient and plotted versus time on a semilogarithmic scale. The fractional turnover rate (FTR) of plasma VLDL B-apoprotein was calculated from $t^{1 / 2}$ of the disappearance curve.

The circulating mass of VLDL B-apoprotein was determined from the plasma concentration of this protein and the total volume. The absolute turnover rate or the daily plasma VLDL B-apoprotein flux was then calculated as follows:

VLDL B-apoprotein turnover $(\mathrm{mg} / \mathrm{kg} /$ day $)=$

circulating mass in mg XFTR $\left(\mathrm{h}^{-1}\right)$ X24

body weight in $\mathrm{kg}$

\section{B. Plasma FFA Flux Rate}

Plasma FFA flux was measured using a tracer dose (25 $\mathrm{uCi}$ ) of ${ }^{14} \mathrm{C}$-palmitate infused over a period of two hours [18]. The labelled palmitate was complexed to $2 \mathrm{ml}$ of a $20 \%$ solution of sterile albumin and infused using a continuous delivery syringe at a rate of 0.2 $\mathrm{uCi} / \mathrm{min}$. Blood was withdrawn every ten minutes during the second hour of infusion to estimate the plasma FFA concentration and radioactivity. FFA concentration was measured in duplicate samples by the method of Trout et al. [19]. The free fatty acids were then extracted in alkaline ethylene glycol and counted for radioactivity. Plasma FFA flux rate (ueq $/ \mathrm{kg} / \mathrm{h}$ ) was determined from:

Rate of infusion of labelled palmitate $(\mathrm{dpm} / \mathrm{h})$ specific activity of plasma FFA at equiliprium (dpm/ueq)

body weight in $\mathrm{kg}$

\section{Other Methods}

Oral glucose tolerance tests were performed after an overnight fast using a glucose load of $1 \mathrm{~g} / \mathrm{kg}$ body weight. Samples of blood were withdrawn at half hourly intervals for two hours for measurement of plasma glucose [20] and immunoreactive insulin [21]. The insulin area under the curve was calculated as described previously [22]. The triglyceride and cholesterol content of total plasma or lipoprotein fractions were determined on appropriate aliquots using the methods of Cramp and Robertson [23] and Robertson and Cramp [24].

\section{Results}

\section{Plasma Triglyceride and Lipoprotein Concentration}

In the hypertriglyceridaemic patients plasma VLDL triglycerides constituted $78-90 \%$ of the total plasma triglycerides, indicating that the hypertriglyceridaemia in all patients was due to excess VLDL. The observation that the plasma VLDL B-apoprotein comprised $40-64 \%$ of the total VLDL proteins in the normal and hypertriglyceridaemic subjects and that the triglyceride to protein ratio was similar in both groups suggests that the composition of the circulating VLDL molecules was unchanged in the hypertriglyceridaemic patients.

Though in some of the patients the total plasma cholesterol concentration was higher than that of the normal controls, in only one patient (patient No. 10) was this increase associated with $\mathrm{LDL}$ cholesterol 
slightly above the upper limit of normal $(150 / \mathrm{mg} / 100$ $\mathrm{ml})$. This patient, therefore, could be classified as having type Ilb hyperlipoproteinaemia. None of the patients had an abnormal accumulation of triglycerides ( $2 \%$ of the total plasma level) in the intermediate density lipoproteins (density 1.006-1.009), excluding the diagnosis of type III hyperlipoproteinaemia. The lipoprotein abnormality in the remaining eight patients was therefore consistent with a pattern similar to that seen in Fredrickson type IV hyperlipoproteinaemia.

\section{Plasma VLDL B-Apoprotein Turnover}

Figure $1 \mathrm{a}$ and $\mathrm{b}$ shows a set of reprensentative radioactivity decay curves obtained in a normal subject. Figure 1a shows the curves for the total VLDL and for the B-apoprotein in plasma VLDL obtained by precipitation with tetramethylurea. It is evident that the disappearance rate of total ${ }^{131} \mathrm{I}$ VLDL in plasma is complex and could be resolved into several exponentials representing the decay rates of several labelled components of the molecule. On the other hand, the decay rate of the B-apoprotein in plasma VLDL was found to conform to a single exponential function with a disappearance half time $\left(\mathrm{t}^{1 / 2} / 2\right)$ of $2-4 \mathrm{~h}$.

Figure $1 \mathrm{~b}$ shows the disappearance of radioactivity from labelled VLDL preincubated with the subject's own HDL rich plasma and reisolated by ultracentrifugation before the injection. It can be seen that the decay curve produces a single exponential with $t^{1 / 2}$ value which was similar to that of the $\mathrm{B}$-apoprotein isolated by the tetramethylurea precipitation as shown in Figure 1a. Indeed, preliminary experiments performed in four normal subjects and three patients with hypertriglyceridaemia showed that the decay rate of preincubated labelled VLDL agreed closely with the decay rate of the B-apoprotein in this lipoprotein fraction $(p<0.001)$. It was therefore assumed in all subsequent studies that the fractional turnover rate of preincubated ${ }^{131}$ I VLDL represented the flux rate of the B-apoprotein in plasma VLDL.

The $\mathfrak{t}^{1 / 2}$ of plasma VLDL determined from the radioactivity curves obtained in normal subjects varied between 2.17 and $3.15 \mathrm{~h}$, while the absolute daily plasma turnover of VLDL B-apoprotein was $25.9 \pm 2.9 \mathrm{mg} / \mathrm{kg} /$ day (range 12.5-33.6). Since the ratio of triglyceride to B-apoprotein in plasma VLDL was approximately $10: 1$, this turnover rate would correspond to a triglyceride production rate of $125-336 \mathrm{mg} / \mathrm{kg} / \mathrm{day}$. This value is approximately similar to that reported by our group [18] as well as others $[25,26]$ in subjects in whom the VLDL molecules were labelled endogenously in the triglyceride moiety.
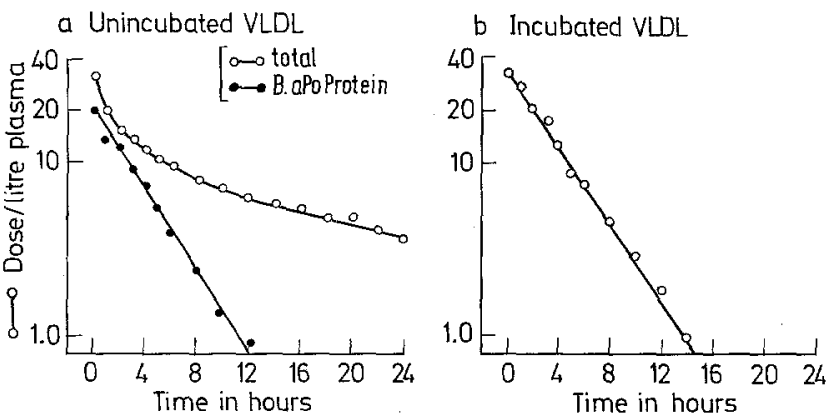

Fig. 1. Effect of preincubation of labelled VLDL with HDL rich plasma on the in vivo disappearance of plasma VLDL radio-activity. 1a: Disappearance curve of total ${ }^{131} \mathrm{I}$ VLDL and ${ }^{131} \mathrm{I}$ VLDL B-apoprotein obtained by tetramethylurea precipitation. 1b: VLDL was labelled with ${ }^{125} \mathrm{I}$ and preincubated with the patient's own HDL rich plasma and reseparated by ultracentrifugation. For further details see under Methods

In the four patients with idiopathic hypertriglyceridaemia the increase in circulating mass of VLDL B-apoprotein was associated with a concordant increase in the turnover rate of this apoprotein. Similarly, an increase in the turnover rate of VLDL B-apoprotein was observed in the three patients with maturity onset diabetes. These results suggest that the hyperlipoproteinaemia in these patients was associated with an enhancement in the production of VLDL B-apoprotein. In contrast, the two subjects with lipodystrophy had turnover rates within the normal range suggesting that the increase in plasma VLDL in these subjects was associated with impaired removal of the carrier B-apoprotein in plasma VLDL.

\section{Plasma FFA Flux Rate}

Table 3 shows that in the patients with idiopathic hypertriglyceridaemia and maturity onset diabetes, the plasma FFA concentration was higher than that of the controls. The circulating mass of FFA in these patients was elevated 3-4 fold above the values seen in the normolipaemic subjects. This elevation was associated with a significant enhancement of plasma FFA flux. In the patients with lipodystrophic diabetes on the other hand the plasma FFA concentration and flux were close to the lower limits of the normal range.

Figure 2 shows that in all the subjects studied there appeared to be a close correlation between the plasma FFA flux and the turnover of plasma VLDL B-apoprotein suggesting a causal relationship between the enhanced lipolysis and the increased VLDL B-apoprotein production. In these patients, however, no significant correlation was observed between the plasma FFA flux and either their abosulte or relative body weights. $(\mathrm{P}=0.15$ and 0.12 respectively.) 
Table 3. Flux rates of plasma FFA and VLDL B-apoprotein in normal subjects and in patients with hypertriglyceridaemia

\begin{tabular}{|c|c|c|c|c|c|}
\hline \multirow{2}{*}{$\begin{array}{l}\text { Subjects } \\
\text { No }\end{array}$} & \multicolumn{2}{|l|}{ FFA } & \multirow[b]{2}{*}{$\begin{array}{l}\text { Circulating } \\
\text { mass } \\
(\mathrm{mg})\end{array}$} & \multicolumn{2}{|c|}{ VLDL B-apoprotein } \\
\hline & 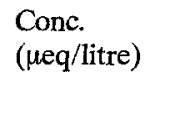 & $\begin{array}{l}\text { Flux rate } \\
\mu \mathrm{eq} / \mathrm{kg} / \mathrm{h}\end{array}$ & & $\begin{array}{l}\text { FTR } \\
\left(\mathrm{h}^{-1}\right)\end{array}$ & $\begin{array}{l}\text { Turnover rate } \\
\text { (mg/kg/day) }\end{array}$ \\
\hline \multicolumn{6}{|c|}{ Normotriglyceridaemic subjects $(n=8)$} \\
\hline 1 & 878 & 189 & 150 & 0.28 & 18.2 \\
\hline 2 & 1014 & 237 & 360 & 0.31 & 32.6 \\
\hline 3 & 1040 & 201 & 180 & 0.32 & 25.9 \\
\hline 4 & 978 & 193 & 160 & 0.32 & 19.2 \\
\hline 5 & 480 & 169 & 120 & 0.30 & 12.5 \\
\hline 6 & 1024 & 285 & 580 & 0.22 & 33.6 \\
\hline 7 & 1004 & 259 & 420 & 0.24 & 33.0 \\
\hline 8 & 984 & 219 & 290 & 0.29 & 31.7 \\
\hline $\begin{array}{l}\text { Mean } \pm S E M \\
\text { Range }\end{array}$ & $\begin{array}{l}925 \pm 66 \\
(480-1040)\end{array}$ & $\begin{array}{l}219 \pm 14 \\
(169-285)\end{array}$ & $\begin{array}{l}282 \pm 57 \\
(120-580)\end{array}$ & $\begin{array}{l}0.28 \pm 0.01 \\
(0.22-0.32)\end{array}$ & $\begin{array}{l}25.9 \pm 2.9 \\
(12.5-33.6)\end{array}$ \\
\hline \multicolumn{6}{|c|}{ Endogenous hypertriglyceridaemia $(n=7)$} \\
\hline 9 & 1850 & 340 & 1390 & 0.16 & 49.5 \\
\hline 10 & 1980 & 395 & 680 & 0.21 & 37.7 \\
\hline 11 & 2960 & 442 & 760 & 0.21 & 50.4 \\
\hline 12 & 1650 & 343 & 910 & 0.23 & 47.3 \\
\hline 13 & 1890 & 480 & 1960 & 0.10 & 56.5 \\
\hline 14 & 2010 & 375 & 1990 & 0.07 & 46.8 \\
\hline 15 & 2200 & 322 & 1890 & 0.06 & 39.6 \\
\hline $\begin{array}{l}\text { Mean } \pm S E M \\
\text { Range }\end{array}$ & $\begin{array}{l}2077 \pm 160 \\
(1850-2960)\end{array}$ & $\begin{array}{l}385 \pm 22 \\
(322-480)\end{array}$ & $\begin{array}{l}1368 \pm 221 \\
(680-1990)\end{array}$ & $\begin{array}{l}0.15 \pm 0.023 \\
(0.06-0.23)\end{array}$ & $\begin{array}{l}46.8 \pm 2.4 \\
(37.7-56.5)\end{array}$ \\
\hline \multicolumn{6}{|c|}{ Lipodystrophic diabetes $(n=2)$} \\
\hline 16 & 420 & 170 & 970 & 0.05 & 72.4 \\
\hline 17 & 516 & 150 & 1000 & 0.035 & 18.6 \\
\hline
\end{tabular}

FTR = fractional turnover rate

Circulating mass is calculated from the mean steady state concentration multiplied by the plasma volume taken as $5 \%$ of the body weight in $\mathrm{kg}$

\section{Plasma Insulin Levels}

Figure 3 shows the fasting plasma insulin concentrations and the insulin responses following an oral glucose load. Inappropriately elevated insulin levels were observed in all the hypertriglyceridaemic patients. Thus the fasting plasma insulin levels in the seven patients with endogenous hypertriglyceridaemia averaged $21 \pm 3$ (range 5-30) $\mu \mathrm{U} / \mathrm{ml}$ which is significantly higher than that seen in the normotriglyceridaemic subjects (Mean \pm SEM $7 \pm 1$, range $4-10 \mu \mathrm{U} / \mathrm{ml}$ ). Also in the hypertriglyceridaemic patients the mean insulin area was $503 \pm 84$, (range 116-786) which was significantly higher than that of the controls (Mean \pm SEM $113 \pm 20$, range 96-142).

In the two patients with diabetic lipodystrophy the fasting plasma insulin levels were 40 and $62 \mu \mathrm{U} / \mathrm{ml}$. The insulin areas obtained during an oral glucose tolerance test were the highest among all the subjects studied.

Though hyperinsulinaemia was evident in all the hypertriglyceridaemic subjects, examination of the individual values showed a poor correlation between the turnover rates of VLDL B-apoprotein and either the fasting plasma insulin level $(\mathrm{r}=0.254, \mathrm{P}=0.15)$ or the insulin areas $(r=0.295, p=0.1)$.

\section{Discussion}

The data presented in this study showing enhanced turnover of plasma VLDL B-apoprotein in some patients with endogenous hypertriglyceridaemia indicate that the increased triglyceride turnover seen in these patients $[2,3,7]$ is associated with an increased production of plasma VLDL B-apoprotein. Indeed in a previous study [8] we have demonstrated a close correlation between the turnover of endogenous plasma triglycerides and that of VLDL carrier apoprotein measured simultaneously in hypertriglyceridaemic patients.

Increased VLDL production could result from increased de novo hepatic synthesis of fatty acids in response to hyperinsulinaemia and/or from the enhanced supply of plasma FFA available for hepatic esterification to triglycerides. Experiments with rat 




Fig. 2. Correlation between plasma FFA flux and VLDL B-apoprotein turnover. $O=$ normotriglyceridaemic subjects; $-=$ endogenous hypertriglyceridaemia; $\mathbf{\Delta}=$ hypertriglyceridaemia with lipodystrophy
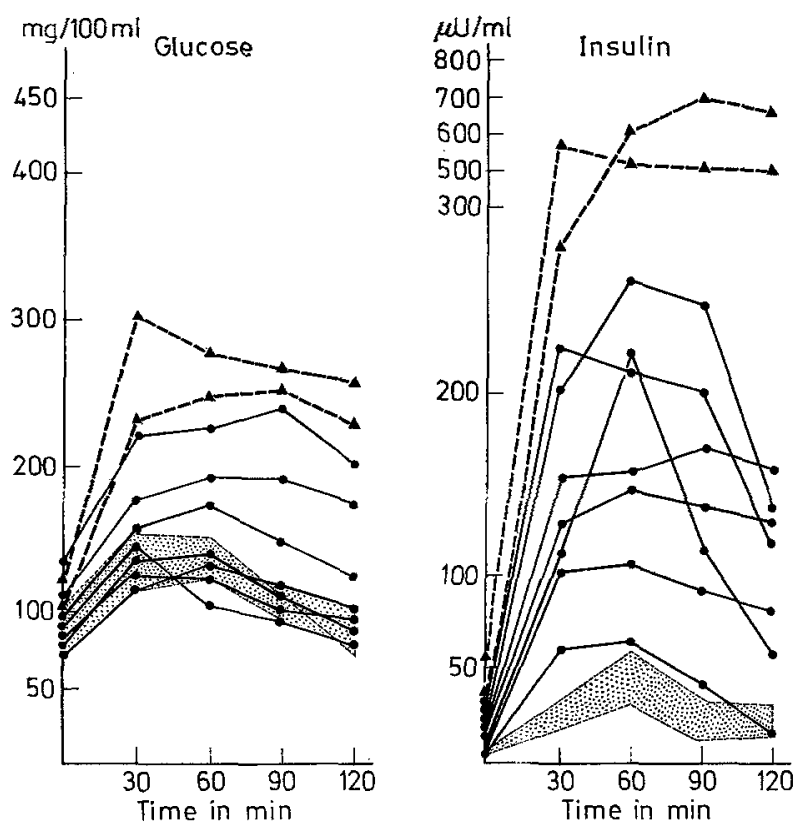

Fig. 3. Glucose and insulin levels during an oral glucose tolerance test. Shaded areas represent the normal ranges. Other symbols as in Figure 2

liver have shown that insulin increased the incorporation of labelled glucose into triglycerides and enhanced the subsequent release of VLDL molecules into the medium $[27,28,29]$. On the basis of these observations and the finding of a close correlation between the elevation of plasma insulin and the increase in triglyceride turnover Reaven et al. [2] suggested that hyperinsulinaemia is the major pathogenetic mechanism in the development of endogenous hypertriglyceridaemia in man. Our results, however, do not support this hypothesis. Although hyperinsulinaemia was found in all the hypertriglyceridaemic patients no correlation was demonstrable between the plasma insulin level and the turnover of VLDL B-apoprotein. Furthermore, in the two patients with lipodystrophy the production rate of the plasma VLDL B-apoprotein was normal, despite the fact that the insulin responses were the highest observed amongst our patients.

Evidence from other sources supports our conclusion that hyperinsulinaemia alone is not sufficient to induce the increased hepatic VLDL production in these patients. Thus Schlierf and Kinsell [30] have reported that the administration of insulin does not produce a significant elevation in plasma triglyceride concentration. Furthermore, in patients with hyperinsulinaemia due to a functioning islet cell tumour hypertriglyceridaemia does not occur even with high carbohydrate feeding [1].

The observations in the present study, on the other hand, suggest that the increased supply of free fatty acid constitutes the major determinant factor in stimulating hepatic VLDL synthesis in patients with endogenous hypertriglyceridaemia. Thus the turnover of plasma FFA was increased and correlated closely with the enhanced production of plasma VLDL B-apoprotein. A similar correlation was also demonstrable between the FFA flux and the turnover of VLDL triglycerides in a previous study [7]. The finding of a normal VLDL B-apoprotein flux and VLDL triglyceride turnover (unpublished) in the two subjects with lipodystrophy further support our view since in these patients the plasma FFA flux was not elevated.

The greater importance of plasma FFA in determining the hepatic VLDL output in man as compared to fatty acids derived from carbohydrate sources has been pointed out in several studies [31,32]. Recently, Barter et al. [9], and Barter and Nestel [10], using a continuous infusion of ${ }^{3} \mathrm{H}$ palmitate and ${ }^{14} \mathrm{C}$ glucose, demonstrated that virtually all newly formed VLDL triglycerides, both in normal and hypertriglyceridaemic subjects receiving a blanced diet, were derived from hepatic esterification of plasma FFA. On the other hand, hepatic lipogenesis from glucose constituted a minor source of plasma triglycerides. Thus the increased availability of FFA, as seen in patients with endogenous hypertriglyceridaemia, could induce an increase in plasma VLDL production. This effect appears to be independent of the prevailing insulin level. Thus Schlierf and Dorow [33] and Schlierf et al. [34] have reported that the nocturnal rise in plasma triglycerides coincided with the overnight enhancement of lipolysis, when the plasma insulin levels were very low. Also, in juvenile ketoacidotic diabetics the increased plasma FFA flux enhanced the hepatic re- 
lease of triglycerides at a time when insulin deficiency was most marked [35]. These results indicate that an "insulinised" liver is not a necessity for the enhanced lipolysis to increase hepatic triglyceride production and that the existence of hepatic resistance to insulin action need not influence the effect of the increased FFA flux.

The mechanisms underlying the increased FFA flux seen in patients with endogenous hypertriglyceridaemia are not clear. This increase is not a manifestation of increased adiposity since none of our patients was markedly obese and no correlation was demonstrable between the body weight and FFA flux. Also the increased FFA flux could not be due to enhanced recycling of FFA from plasma triglycerides or increased transport of FFA between the plasma and the extravascular space, since estimates of these parameters have been shown in a previous study to be within the normal range [18]. The likelihood therefore is that the increased circulating FFA was due to enhanced lipolysis; in the presence of hyperinsulinaemia this indicates a state of insulin resistance in adipose tissue. Indeed recent studies [36] have shown decreased sensitivity of the antilipolytic response to insulin in adipose tissue obtained from patients with endogenous hypertriglyceridaemia.

The insulin resistance in adipose tissue, however, probably does not account for the impaired glucose tolerance observed in some patients with endogenous hypertriglyceridaemia since Björntorp et al. [37] have reported that less than $5 \%$ of the total glucose consumption could be attributed to adipose tissue metabolism in man. Also Sjöström et al. [38], using cell free homogenates of adipose tissue, indicated that the maximum lipogenesis by this tissue accounted for a minor fraction of the daily glucose flux. It is more likely therefore that the resistance to insulin action involves the liver in addition to adipose tissue. This conclusion certainly applies to patients with lipodystrophy in view of the marked hyperglycaemia observed in these patients despite extremely high prevailing insulin levels.

Further studies however are required to identify the biochemical derangement responsible for the insulin resistance in these subjects.

\section{References}

1. Farquhar, J. W., Frank, A., Gross, R. C., Reaven, G. M.: Glucose, insulin and triglyceride responses to high and low carbohydrate diets in man. J. clin. Invest. 45, 1648-1656 (1966)

2. Reaven, G. M., Lerner, R. L., Stern, M. P., John, W., Nakaknishi, R.: Role of insulin in endogenous hypertriglyceridemia.J. clin. Invest. 46, 1756-1767 (1967)
3. Olefsky, J. M., Farquhar, J. W., Reaven, G. M.: Reappraisal of the role of insulin in hypertriglyceridemia. Amer. J. Med. 57, 551-560 (1974)

4. Havel, R.: Lipid transport and insulin resistance. Excerpta med. (Amst.) 20, 353-359 (1973)

5. Bray, G. A., Yorks, D. A.: Genetically transmitted obesity in rodents. Physiol. Rev. 51, 598-676 (1971)

6. Kahn, C. R., Neville, D. M., Jr., Roth, J.: Insulin-receptor interaction in the obese-hyperglycaemic mouse. J. biol. Chem. 248, 244-251 (1973)

7. Adams, P. W., Kissebah, A. H., Harrigan, P., Stokes, T., Wynn, V.: The kinetics of plasma free fatty acid and triglyceride transport in patients with idiopathic hypertriglyceridaemia and their relation to carbohydrate metabolism. Europ. J. clin. Invest. 4, 149-161 (1974)

8. Kissebah, A. H., Alfarsi, S., Adams, P. W., Seed, M., Folkard, J., Wynn, V.: Transport kinetics of plasma free fatty acids, very low density lipoprotein triglycerides and apoprotein in patients with endogenous hypertriglyceridaemia: Effects of 2, 2-Dimethyl, 5 (2,5-xylyoxy) valeric acid therapy. Atherosclerosis 24, 199-218 (1976)

9. Barter, P. J., Nestel, P. J., Carroll, K. F.: Precursors of plasma triglyceride fatty acid in humans. Effects of glucose consumption, clofibrate administration and alcoholic fatty liver. Metabolism 21, 117-124 (1972)

10. Barter, P. J., Nestel, P. J.: Precursors of plasma triglyceride fatty acids in obesity. Metabolism 22, 779-785 (1973)

11. Hatch, F. T., Lees, R. S.: Practical methods for plasma lipoprotein analysis. In: Advances in lipid research, 6 (eds. R. Paoletti, D. Kritchevsky), p. 16. New York-London: Academic Press 1968

12. MacFarlane, A. S.: Efficient trace-labelling of proteins with iodine. Nature (Lond.) 182, 53 (1968)

13. Stern, H. S., McAfee, J. G., Follie, I.: Paper chromatography of iodinated proteins. In: Radioactive pharmaceuticals, Chapt. 19 (eds. G. A. Andres, R. M. Kinsley, H. N. Wagner), p. 359. U. S. Atomic Energy Commission 1966

14. Eisenberg, S., Rachmilewitz, D., Stein, O., Stein, Y.: Metabolic non-homogeneity of lecithin and cholesterol in aortae. Biochim. biophys. Acta. (Amst.) 231, 198-207 (1971)

15. Kanc, J. P.: A rapid electrophoretic technique for identification of subunit species of apoproteins in serum lipoproteins. Analyt. Biochem. 53, 350-356 (1973)

16. Bilheimer, D. W., Eisenberg, S., Levy, R. I.: The metabolism of very low density lipoprotein proteins. I. Preliminary in vitro and in vivo observations. Biochim. biophys. Acta (Amst.) 260, 212-221 (1972)

17. Lowry, O. H., Rosebrough, N. J., Farr, A. L., Randall, R. J.: Protein measurement with folinphenol reagent. J. biol. Chem. 193, 265-275 (1951)

18. Kissebah, A. H., Adams, P. W., Wynn, V.: Plasma free fatty acid and triglyceride transport kinetics in man. Clin. Sci. and Mol. Med. 47, 259-278 (1974)

19. Trout, D. L., Estes, E. H., Friedberg, S. J.: Titration of free fatty acid of plasma. A study of current methods and a new modification. J. Lipid Res. 1, 199-202 (1960)

20. Cramp, D. G.: New automated method for measuring glucose by glucose oxidase. J. clin. Path. 20, 910-912 (1967)

21. Albano, J. D., Ekins, R. P., Maritz, G., Turner, R. C.: A sensitive precise radio-immuno assay of serum insulin relying on charcoal separation of bound and free hormone moieties. Acta endocr. (Kbh.). 70, 487-509 (1972)

22. Wynn, V., Doar, J. W.: Some effects of oral contraceptives on carbohydrate metabolism. Lancet $1966 \mathrm{H}, 715-720$

23. Cramp, D. G., Robertson, G. R.: The fluorimetric assay of triglyceride by a semi-automated method. Analyt. Biochem. 25, 246-251 (1968) 
24. Robertson, G. R., Cramp, D. G.: An evaluation of cholesterol determination in serum and scrum lipoprotein fractions by a semiautomated fluorimetric method. J. clin. Path. 23, 243-251 (1970)

25. Nikkila, E. A., Kekki, M.: Polymorphism of plasma triglyceride kinetics in normal human adult subjects. Acta med. scand. 190, 49-59 (1971)

26. Eaton, R. P., Steinberg, D., Berman, M.: Quantitative evaluation of free fatty acid and triglyceride fatty acid metabolism in man. J. clin. Invest. 44, 1041 (1965)

27. Salans, L. B., Reaven, G. M.: Effects of insulin pretreatment on glucose and lipid metabolism of liver slices from normal rats. Proc. Soc. exp. Biol. (N. Y.) 122, 1208-1213 (1966)

28. Letarte, J., Fraser, T. R.: Stimulation by insulin of the incorporation of $\mathrm{U}^{14} \mathrm{C}$-glucose into lipids released by the liver. Diabetologia 5, 358-364 (1969)

29. Haft, D. E.: Effects of insulin on glucose metabolism by the perfused normal rat liver. Amer. J. Physiol. 213, 219-230 (1967)

30. Schlierf, G., Kinsell, L. W.: Effect of insulin in hypertriglyceridaemia. Proc. Soc. exp. Biol. (N. Y.) 120, 272-278 (1965)

31. Havel, R. J., Kane, J. P., Balasse, E. O., Segal, N., Basso, L. V.: Splanchnic metabolism of free fatty acids and production of triglycerides of very low density lipoproteins in normotriglyceridaemic and hypertriglyceridamic humans. J. clin. Invest. 49, 2017-2035 (1970)

32. Boberg, J., Carlson, L. A., Freyschuss, U.: Determination of splanchnic secretion rate of plasma triglycerides and of total and splanchnic turnover of plasma free fatty acids in man. Europ. J. clin. Invest. 2, 123-132 (1972)
33. Schlierf, G., Dorow, E.: Diurnal patterns of triglycerides, free fatty acids, blood sugar, and insulin during carbohydrate induction in man and their modification by nocturnal suppression of lipolysis. J. clin. Invest. 52, 732-739 (1973)

34. Schlicrf, G., Reinheimer, W., Strassberg, V.: Diurnal patterns of plasma triglycerides and free fatty acids in normal subjects and in patients with endogenous (type IV) hyperlipoproteinaemia. Nutr. Metab. 13, 80-92 (1971)

35. Nikkila, E. A., Kekki, M.: Plasma triglyceride transport kinetics in diabetes mellitus. Metabolism 22, 1-22 (1973)

36. Larsson, B., Bjöntorp, P., Holm, J., Scherstein, T., Sjöström, L., Smith, U.: Adipocyte metabolism in endogenous hypertriglyceridaemia. Metabolism 24, 1375-1389 (1975)

37. Björntorp, P., Krotbrewski, M., Larsson, B.: Effects of feeding states on lipid radioacitivity in liver, muscle and adipose tissue after injection of labelled glucose in the rat. Acta. physiol. scand. 80, 29-38 (1970)

38. Sjöström, L.: Adult human adipose tissue cellularity and metabolism. Acta med. scand. Suppl. 544, 1-53 (1972)

Received: March 15, 1976, and in revised form: July 20, 1976

Dr. A. H. Kissebah

Metabolic Unit

St. Mary's Medical School

London W2

England 